\title{
Electroantennogram responses of male Sphinx perelegans hawkmoths to floral and 'green-leaf volatiles'
}

\author{
Robert A. Raguso ${ }^{1,2}$ \& Douglas M. Light ${ }^{3}$ \\ ${ }^{1}$ Dept. of Biology, Univ. of Michigan. Ann Arbor, MI 48109-1048, USA; ${ }^{2}$ Current address: ARL Div. of \\ Neurobiology and Center for Insect Science, 611 Gould Simpson Building, Univ. of Arizona, Tucson, AZ \\ 85721-0077, USA; ${ }^{3}$ USDA-ARS. Western Regional Research Center, 800 Buchanan St., Albany, CA 94710, USA
}

Accepted: November 25, 1997

Key words: EAG, Sphingidae, olfaction, pollination, Hyles lineata, floral scent, Clarkia breweri, night-blooming flowers

\begin{abstract}
Electroantennograms (EAGs) from field-collected male Sphinx perelegans hawkmoths were recorded in response to 10 individual floral scent compounds identified from Clarkia breweri (Onagraceae), 21 additional volatiles characteristic of other night-blooming flowers, and eight 'green leaf' volatiles. Measurable EAG responses were elicited to all compounds tested, but the most effective antennal stimulants were benzyl acetate, linalool, methyl salicylate and trans-2-hexenal. Mean, pooled EAGs to oxygenated terpenoids, aromatic esters and fatty acid derivatives were larger in magnitude than those in response to aromatic aldehydes/alcohols, monoterpenes and nitrogen-bearing compounds. The rank order of male $S$. perelegans' EAGs did not differ significantly from that of previously recorded responses of male Hyles lineata to the same scent compounds, and EAG magnitudes were generally larger for $S$. perelegans than for $H$. lineata. Both hawkmoth species are shown to have broad olfactory receptivities and could potentially respond to a wide array of plant volatiles as floral attractants.
\end{abstract}

\section{Introduction}

Hawkmoths (Sphingidae: Lepidoptera) are large, primarily nocturnal insects, with powerful, hovering flight and high metabolic demands (Heath \& Adams, 1965; Heinrich, 1971; Bartholomew \& Casey, 1978). Many hawkmoth species meet these demands by foraging for floral nectar; some are important pollinators across diverse temperate (Gregory, 1964; Miller, 1978; Grant, 1983) and tropical habitats (SilberbauerGottsberger \& Gottsberger, 1975; Haber \& Frankie, 1989; Nilsson et al., 1985).

Many hawkmoth-pollinated plants share a number of floral characters putatively associated with hawkmoth attraction, including nocturnal anthesis, pale coloration, sucrose-rich nectar and strong, sweet floral scent (Baker, 1961; Gregory, 1964; Faegri \& van der Pijl, 1972; Miller, 1978; Grant, 1983; Knudsen \& Tollsten, 1993). We have studied one plant, Clarkia breweri (Onagraceae), that appears to have evolved this suite of traits in conjunction with an evolutionary shift from bee- to hawkmoth-pollination (MacSwain et al., 1973; Raguso \& Pichersky, 1995). Previous studies have focused on floral scent production in $C$. breweri and its evolution as a novel reproductive character in the genus Clarkia (Pichersky et al., 1994; Raguso \& Pichersky, 1995; Raguso, 1995; Dudareva et al., 1996), yet its importance in hawkmoth attraction has not yet been determined. Floral scent is typically discussed as a long distance hawkmoth attractant (Tinbergen, 1958; Faegri \& van der Pijl, 1979; Brantjes, 1973; 1978; Nilsson, 1983; Dobson, 1994), but experimental tests are few and results are equivocal. Chemical analyses show that hawkmoth-pollinated flowers emit a diverse array of terpenes, aromatics, fatty acid-derived and nitrogen-bearing compounds (Nilsson, 1983; Tollsten, 1993; Kaiser, 1993; Raguso \& Pichersky, 1995), with low levels of chemical similarity between species (Knudsen \& Tollsten, 1993). Brantjes (1973; 1978) conducted flight tunnel bioassays with two hawkmoth 
species (Deilephila elpenor and Manduca sexta) and concluded that floral scent blends function as 'signstimuli' that release visual search behavior and upwind flight in hawkmoths. However, there have been no comprehensive surveys on physiological or behavioral responses of flower-feeding hawkmoths to different floral scent blends, and little is known about the relative importance of visual vs. olfactory cues in hawkmoth foraging (Knoll, 1925; Kugler, 1971; White et al., 1994).

One approach to studying hawkmoth-flower interactions is to measure the olfactory capabilities of different flower-visiting hawkmoth species. Previously, we recorded electroantennogram (EAG) responses of Hyles lineata, a generalist hawkmoth species that forages during daylight, dusk, and evening throughout North America, to different floral and vegetative odors (Raguso et al., 1996). H. lineata is an important pollinator of $C$. breweri (Raguso, 1995) and similar plants in central California (Grant, 1952; Gregory, 1964; Chase \& Raven, 1975; Hodges, 1995) but visits an extremely broad range of flowering plants throughout its distribution (Fleming, 1970; Kislev et al., 1972). Not surprisingly, it is olfactorily responsive to a broad array of floral and vegetative volatiles including aromatics, fatty-acid derived compounds, and terpenoids, through a wide range of physiologically relevant concentrations (Raguso et al., 1996).

In contrast, the other important hawkmoth pollinator of C. breweri, Sphinx perelegans, is a strictly nocturnal species limited to western North America (Hodges, 1971), and appears to be a relative specialist in terms of larval hostplant use (S. Miller, C. Conlan, unpubl. data). In addition, adult $S$. perelegans moths have been observed foraging at relatively few plant species, including C. breweri, Diplacus aurantiacus (Scrophulariaceae) (Raguso, 1995), Oenothera caespitosa and O. elata (= hookeri, Onagraceae) (Gregory, 1963, 1964). Do the differences in distribution, life history and foraging patterns between these two hawkmoth species predict differences in olfactory receptivity to different plant volatiles, or should the antennae of these and other flower-visiting hawkmoths be expected to detect most/all classes of plant volatiles? Here we measure the EAG responses of male S. perelegans moths to a diverse array of 39 plant volatiles, including floral scent compounds from $C$. breweri and other night-blooming plants as well as vegetative volatiles.

\section{Materials and methods}

Insects. Adult male S. perelegans moths were collected at UV light traps in an oak/pine woodland two km east of Pinnacles National Monument, San Benito Co., CA in May, 1994, and were transported live to Albany, CA. Moths were held in $1 \mathrm{~m}^{3}$ screen cages within the laboratory for $1-2$ days $\left(25^{\circ} \mathrm{C}, \mathrm{L} 12: \mathrm{D} 12\right)$ and fed a $10 \%$ sucrose solution.

Olfactory stimuli. The compounds tested (Table 1) included 10 of the 12 major floral volatiles from C. breweri (Raguso \& Pichersky, 1995), 21 aromatic, terpenoid, and nitrogen-bearing volatiles characteristic of other hawkmoth-pollinated flowers (Nilsson et al., 1985; Kaiser, 1991; Knudsen \& Tollsten, 1993) and eight 'green leaf volatiles' (GLVs), $\mathrm{C}_{6}-\mathrm{C}_{8}$ aliphatic alcohols, aldehydes and esters that are ubiquitous in plant foliage (Visser et al., 1979; Light et al., 1993). Biological justification for our selection of odor stimulants was detailed by Raguso et al. (1996), and includes previous identification from the fragrance of hawkmoth or noctuid moth-pollinated flowers, or structural affinity to one of these compounds, with slight functional group variation. The GLVs appear to be important in insect-plant interactions (e.g. host finding and oviposition) and may provide strong structural contrast to the floral compounds used in our receptivity assays. The sources of test chemicals were Aldrich Chemical Co. and Robert Flath (USDA-ARS, WRRC). Chemical purities ranged from 97-99\% (except amyl salicylate, 75\%; (Z)-jasmone, 70\%; farnesol, 95\%). Test stimulants were prepared as $10 \%$ volumetric solutions in hexane. In the cases of indole, vanillin, and veratraldehyde, diethyl ether was used as a solvent. We prepared odor stimulants within 20 min prior to each experiment by pipetting c. $100 \mu \mathrm{g}$ aliquots of each solution onto filter paper strips, and then allowing the solvent to evaporate for $30 \mathrm{~s}$. The strips were then placed into Pasteur pipettes and stored at $5{ }^{\circ} \mathrm{C}$ until use.

EAG technique. EAG data were measured and recorded on a Tektronix 5113 storage oscilloscope as previously described by Light et al. (1988) and Raguso et al. (1996). We assembled electrodes by inserting silver chloride filaments within drawn-glass capillary tubes containing physiological saline solution (Raguso et al., 1996). In preparation for EAG recordings, live moths were mounted between a cardboard gasket and a grooved plexiglass block, in which the wings were immobilized beneath the cardboard, the body fit snugly 
Table 1. Scent compounds used as antennal stimulants, EAG responses of Sphinx perelegans, and rank order values for both $S$. perelegans and Hyles lineata male hawkmoths

\begin{tabular}{|c|c|c|c|c|c|}
\hline \multirow{2}{*}{$\begin{array}{l}\text { Compound } \\
\text { Class }\end{array}$} & \multirow{2}{*}{$\begin{array}{l}\text { Chemical } \\
\text { formula }\end{array}$} & \multirow{2}{*}{$\begin{array}{l}\text { S. perelegans } \\
\text { EAG }^{1}\end{array}$} & \multicolumn{2}{|c|}{ EAG Rank orders ${ }^{2}$} & \multirow{2}{*}{$\begin{array}{l}\text { Changes } \\
>10\end{array}$} \\
\hline & & & S. perelegans & H. lineata & \\
\hline \multicolumn{6}{|l|}{ Aromatics } \\
\hline amyl salicylate & $\mathrm{C}_{12} \mathrm{H}_{16} \mathrm{O}_{3}$ & $0.45 \pm 0.04$ & 16 & 14 & \\
\hline benzaldehyde & $\mathrm{C}_{7} \mathrm{H}_{6} \mathrm{O}$ & $0.78 \pm 0.08$ & 8 & 22 & $<$ \\
\hline benzyl acetate ${ }^{3}$ & $\mathrm{C}_{9} \mathrm{H}_{10} \mathrm{O}_{2}$ & $0.90 \pm 0.05$ & 1 & 5 & \\
\hline benzyl alcohol & $\mathrm{C}_{6} \mathrm{H}_{6} \mathrm{O}$ & $0.38 \pm 0.04$ & 20 & 36 & $<$ \\
\hline benzyl benzoate ${ }^{3}$ & $\mathrm{C}_{14} \mathrm{H}_{12} \mathrm{O}_{2}$ & $0.26 \pm 0.05$ & 23 & 29 & \\
\hline benzyl salicylate & $\mathrm{C}_{14} \mathrm{H}_{12} \mathrm{O}_{3}$ & $0.33 \pm 0.04$ & 21 & 26 & \\
\hline (E)-cinnamic aldehyde & $\mathrm{C}_{9} \mathrm{H}_{8} \mathrm{O}$ & $0.31 \pm 0.06$ & 30 & 27 & \\
\hline eugenol $^{3}$ & $\mathrm{C}_{10} \mathrm{H}_{12} \mathrm{O}_{2}$ & $0.36 \pm 0.08$ & 17 & 24 & \\
\hline indole $^{4}$ & $\mathrm{C}_{8} \mathrm{H}_{7} \mathrm{~N}$ & $0.33 \pm 0.13$ & 32 & 19 & $>$ \\
\hline methoxy-2-methyl benzoate & $\mathrm{C}_{9} \mathrm{H}_{11} \mathrm{O}_{3}$ & $0.41 \pm 0.04$ & 18 & 12 & \\
\hline methyl anthranylate ${ }^{4}$ & $\mathrm{C}_{8} \mathrm{H}_{9} \mathrm{O}_{2} \mathrm{~N}$ & $0.36 \pm 0.06$ & 29 & 13 & $>$ \\
\hline methyl benzoate & $\mathrm{C}_{8} \mathrm{H}_{8} \mathrm{O}_{2}$ & $0.66 \pm 0.20$ & 14 & 17 & \\
\hline methyl cinnamate & $\mathrm{C}_{10} \mathrm{H}_{10} \mathrm{O}_{2}$ & $0.26 \pm 0.03$ & 33 & 16 & $>$ \\
\hline methyl isoeugenol ${ }^{3}$ & $\mathrm{C}_{11} \mathrm{H}_{14} \mathrm{O}_{2}$ & $0.23 \pm 0.04$ & 22 & 25 & \\
\hline methyl salicylate ${ }^{3}$ & $\mathrm{C}_{8} \mathrm{H}_{8} \mathrm{O}_{3}$ & $0.89 \pm 0.06$ & 5 & 4 & \\
\hline phenylacetaldehyde & $\mathrm{C}_{8} \mathrm{H}_{8} \mathrm{O}$ & $0.44 \pm 0.11$ & 19 & 9 & $>$ \\
\hline 2-phenyl ethanol & $\mathrm{C}_{8} \mathrm{H}_{10} \mathrm{O}$ & $0.45 \pm 0.05$ & 27 & 15 & $>$ \\
\hline vanillin $^{3}$ & $\mathrm{C}_{8} \mathrm{H}_{8} \mathrm{O}_{3}$ & $0.05 \pm 0.04$ & 36 & 34 & \\
\hline veratraldehyde ${ }^{3}$ & $\mathrm{C}_{9} \mathrm{H}_{10} \mathrm{O}_{3}$ & $0.07 \pm 0.02$ & 37 & 30 & \\
\hline \multicolumn{6}{|l|}{ Fatty Acid Derivatives } \\
\hline 2-methyl butyraldoxime ${ }^{4}$ & $\mathrm{C}_{5} \mathrm{H}_{12} \mathrm{ON}$ & $0.43 \pm 0.13$ & 10 & 11 & \\
\hline hexanal & $\mathrm{C}_{6} \mathrm{H}_{12} \mathrm{O}$ & $0.24 \pm 0.05$ & 34 & 31 & \\
\hline (E)-2-hexenal & $\mathrm{C}_{6} \mathrm{H}_{10} \mathrm{O}$ & $1.05 \pm 0.13$ & 2 & 33 & \\
\hline hexan-1-ol & $\mathrm{C}_{6} \mathrm{H}_{14} \mathrm{O}$ & $1.26 \pm 0.25$ & 35 & 2 & $>$ \\
\hline (Z)-3-hexen-1-ol & $\mathrm{C}_{6} \mathrm{H}_{12} \mathrm{O}$ & $0.79 \pm 0.07$ & 7 & 8 & \\
\hline (E)-2-hexen-1-ol & $\mathrm{C}_{6} \mathrm{H}_{12} \mathrm{O}$ & $0.70 \pm 0.15$ & 13 & 7 & \\
\hline (Z)-3-hexenyl acetate & $\mathrm{C}_{8} \mathrm{H}_{14} \mathrm{O}_{2}$ & $0.66 \pm 0.21$ & 9 & 3 & \\
\hline (E)-2-hexenyl acetate & $\mathrm{C}_{8} \mathrm{H}_{14} \mathrm{O}_{2}$ & $0.36 \pm 0.10$ & 26 & 6 & $>$ \\
\hline hexyl acetate & $\mathrm{C}_{8} \mathrm{H}_{16} \mathrm{O}_{2}$ & $1.15 \pm 0.29$ & 4 & 23 & $<$ \\
\hline (Z)-jasmone & $\mathrm{C}_{11} \mathrm{H}_{16} \mathrm{O}$ & $0.43 \pm 0.12$ & 25 & 25 & \\
\hline methyl jasmonate & $\mathrm{C}_{13} \mathrm{H}_{20} \mathrm{O}_{3}$ & - & - & $* *$ & \\
\hline \multicolumn{6}{|l|}{ Monoterpenes } \\
\hline 1,8 cineole & $\mathrm{C}_{10} \mathrm{H}_{18} \mathrm{O}$ & $0.66 \pm 0.15$ & 6 & 35 & $<$ \\
\hline geraniol & $\mathrm{C}_{10} \mathrm{H}_{18} \mathrm{O}$ & $0.49 \pm 0.08$ & 24 & 21 & \\
\hline limonene & $\mathrm{C}_{10} \mathrm{H}_{18} \mathrm{O}$ & $0.33 \pm 0.06$ & 31 & 28 & \\
\hline linalool $^{2}$ & $\mathrm{C}_{10} \mathrm{H}_{18} \mathrm{O}$ & $0.92 \pm 0.08$ & 3 & 1 & \\
\hline linalool oxides (Z/E-furanoid) ${ }^{3}$ & $\mathrm{C}_{10} \mathrm{H}_{18} \mathrm{O}_{2}$ & $0.55 \pm 0.14$ & 11 & 10 & \\
\hline linalool oxide (Z-pyranoid) $)^{3}$ & $\mathrm{C}_{10} \mathrm{H}_{18} \mathrm{O}_{2}$ & - & - & $* *$ & \\
\hline myrcene & $\mathrm{C}_{10} \mathrm{H}_{16}$ & $0.53 \pm 0.38$ & 15 & 37 & $<$ \\
\hline (E)- $\beta$-ocimene & $\mathrm{C}_{10} \mathrm{H}_{16}$ & $0.63 \pm 0.02$ & 12 & 32 & $<$ \\
\hline allo-ocimene & $\mathrm{C}_{10} \mathrm{H}_{16}$ & - & - & $* *$ & \\
\hline \multicolumn{6}{|l|}{ Sesquiterpenes } \\
\hline germacrene D & $\mathrm{C}_{15} \mathrm{H}_{24}$ & $0.39 \pm 0.08$ & $* *$ & - & \\
\hline farnesol & $\mathrm{C}_{15} \mathrm{H}_{26} \mathrm{O}$ & $0.28 \pm 0.06$ & 28 & 18 & $>$ \\
\hline nerolidol $^{3}$ & $\mathrm{C}_{15} \mathrm{H}_{26} \mathrm{O}$ & $0.33 \pm 0.04$ & $* *$ & - & \\
\hline
\end{tabular}

${ }^{1}$ Mean EAGs (absolute values of corrected $\mathrm{mV}$ responses) \pm standard errors. ${ }^{2}$ Tabulated from data expressed as \% of standard stimulus. ${ }^{3}$ Identified in floral headspace of Clarkia breweri. ${ }^{4}$ Compounds bearing Nitrogen atoms. **Compound used in experiments with Sphinx or Hyles, but not with both species. 
within the plexiglass groove, and the five terminal (right) antennal segments were excised. The recording electrode was inserted into the antennal cavity, while the ground electrode was inserted into the head at the base of the antenna. Antennae were bathed continuously in a filtered air stream and $1 \mathrm{~s}$ test stimulations were presented in randomized order as previously described, each stimulus followed by a $60 \mathrm{~s}$ purge period (Raguso et al., 1996). For each compound tested, EAGs were recorded from four male moths. Control stimuli ( $1 \mu \mathrm{L}$ of hexane solvent per filter paper) and standard stimuli ( $1 \mu \mathrm{L}$ of $1 \%$ linalool in hexane per filter paper) were interspersed about every fifth compound tested.

Treatment of EAG data. EAG responses (measured in $\mathrm{mV}$ ) to test compounds were adjusted to compensate for solvent and/or mechanosensory artifacts by subtracting the accompanying control EAG, yielding corrected $\mathrm{mV}$ data (Reed et al., 1987; Light et al., 1988, Gabel et al., 1992). In order to examine relative antennal receptivity to all scent compounds, which varied two-fold in molecular weight and three-fold in volatility, we standardized the EAG data by expressing mean corrected mV EAG data as a percent of the standard stimulus, $1 \%$ linalool. In addition, we compared the EAGs of male $S$. perelegans with previously published data from male H. lineata (Raguso et al., 1996). We ranked EAG responses (\% of standard) to the 37 scent compounds common to both studies in descending order of magnitude for each species, and then compared rank orders using Spearman's Rank Correlation Coefficient (Sokal \& Rohlf, 1981).

\section{Results}

EAG responses. All test stimulants elicited measurable EAG traces that were generally similar in shape and greater than those observed for hexane controls. Of the ten $C$. breweri floral volatiles tested, the largest amplitude EAGs $(>0.4 \mathrm{mV})$ were observed in response to linalool, methyl salicylate, benzyl acetate, and furanoid linalool oxide (Table 1). Vanillin, veratraldehyde, and methylisoeugenol were relatively poor antennal stimulants for male $S$. perelegans moths, as they were for male $H$. lineata in previous experiments (Raguso et al., 1996). Mean EAG responses to the 21 additional floral scent compounds varied from medium $(0.25 \mathrm{mV}$, e.g., methyl cinnamate) to large amplitudes $(>0.6 \mathrm{mV}$, e.g., 1,8 cineole, benzalde-

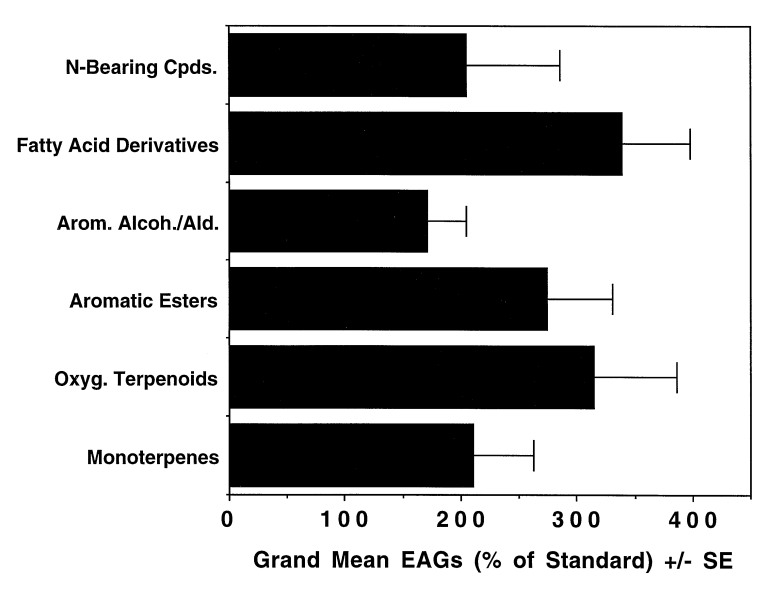

Figure 1. Summary of male $S$. perelegans' EAG responses to different chemical classes, as derived from pooling and averaging the mean EAG responses to each test compound belonging to a given chemical class. Relative responses are expressed as $\%$ of response to standard stimulus ( $1 \% \mathrm{v} / \mathrm{v}$ linalool in hexane).

hyde) (Table 1). Large compounds of low volatility, such as germacrene D, nerolidol, and benzyl salicylate were relatively potent stimulants. Nearly all of the smaller, more volatile GLVs, elicited large amplitude EAGs, especially hexan-1-ol, hexyl acetate and trans-2-hexenal (Table 1). For comparative purposes, $S$. perelegans' EAG responses to different chemical classes of plant odorants are summarized (Figure 1 ) as pooled derived grand means ( $\%$ of standard). Aromatic aldehydes/alcohols, monoterpenes, and nitrogenbearing compounds evoked mean EAGs of moderate amplitudes, while aromatic esters, oxygenated terpenoids, and fatty-acid derivatives evoked generally large EAGs.

EAG rank orders. Rank orders of mean EAGs, expressed as a percent of the standard stimulus, are listed in Table 1 along with previously published rank orders of male $H$. lineata EAGs for the same compounds (Raguso et al., 1996). EAG ranks for male $S$. perelegans and $H$. lineata were significantly correlated (Spearman's $\rho=0.366, \mathrm{P}=0.026, \mathrm{~N}=37$ compounds common to both experiments), but ranks differed by greater than 10 places for $38 \%$ of the test compounds (Table 1). Benzaldehyde, 1,8 cineole, myrcene, hexyl acetate, and trans-2-hexenal were potent antennal stimulants for $S$. perelegans, but poor stimulants for $H$. lineata. The converse was true for (E)2-hexenyl acetate, 2-phenylethanol, indole and methyl anthranylate. 


\section{Discussion}

The antennae of wild-caught adult male $S$. perelegans responded to a broad array of plant-derived olfactory stimulants representing numerous chemical moiety classes, variations in carbon skeleton, molecular weight and volatility. Given the overall similarity in EAG magnitudes and rank orders between male and female $H$. lineata observed in previous studies (Raguso et al., 1996), we suspect that male and female $S$. perelegans will have comparable olfactory receptivities to plant odorants. The results of this study establish that male $S$. perelegans hawkmoths can detect the volatile compounds emitted from flowers of $C$. breweri, which they visit and pollinate in central California (Raguso, 1995), and are consistent with the hypothesis that these fragrance compounds could function as olfactory attractants (MacSwain et al., 1973; Raguso \& Pichersky, 1995). Behavioral bioassays will be needed to directly test this hypothesis. In addition, this study demonstrates that male $S$. perelegans moths can detect scent compounds that typify other nightblooming plant species, some of which are similar to those identified from $C$. breweri flowers, as well as small, aliphatic GLVs that are more characteristic of wounded vegetation (Visser et al., 1979; Light et al., 1993). The large EAG responses of male $S$. perelegans and $H$. lineata males to many of the 'green leaf' volatiles (Table 1), semiochemicals usually discussed as hostplant attractants for female herbivorous insects (Visser \& Avé, 1978), underscore the potential importance of vegetative volatiles as modifiers of olfactory responses to sex pheromones (Dickens et al., 1993; Light et al., 1993) and nectar foraging behavior (Beker et al., 1989) in these phytophagous insects.

When combined with previously published data for wild $H$. lineata (Raguso et al., 1996) and laboratorybred Manduca sexta (Light, unpubl. data), our results suggest that both specialist and generalist nectarforaging hawkmoths have broad olfactory receptivities and are capable of responding to complex, multicomponent floral and vegetative odorant blends with constituents from diverse chemical classes. This is an intuitive result, given the spatial and temporal variation in floral resources encountered by hawkmoths (Kislev et al., 1972; Haber \& Frankie, 1989) and the low levels of chemical similarity in the fragrances emitted by these plants (Knudsen \& Tollsten, 1993; R. Raguso \& M. Willis, unpubl. data). Our battery of odorant stimulants did not include the sulfur bearing compounds characteristic of nocturnal bat-pollinated flowers (Knudsen
\& Tollsten, 1995) nor the aliphatic esters and lactones that typify the odors of many ripe fruits (Fröhlich et al., 1989; Flath et al., 1990; McGrath \& Karahadian, 1994). However, considering hawkmoths' opportunistic use of these additional food sources (Baker, 1961), it would not be surprising if their antennae also were generally receptive to the above classes of odorants.

$S$. perelegans and $H$. lineata are sympatric and share a subset of floral resources in central California, as is suggested by the similarity in their mean proboscis lengths (30-34 mm) and observed foraging behavior (Raguso, 1995). Although male $S$. perelegans and $H$. lineata differ somewhat in EAG rank orders (Table 1) and magnitudes (Raguso et al., 1996), it is unlikely that these differences bear any behavioral significance. Males of $S$. perelegans are significantly larger, on average, than those of $H$. lineata, (body mass and forewing length, $\mathrm{P}<0.005)$ and some differences in EAG magnitude may be attributable to their larger size and longer antennae. Alternatively, incongruities in mean EAGs and rank orders may reflect differences in foraging experience, genetic endowment of antennal receptors, or the small sample sizes ( $\mathrm{N}$ $=4$ and 5 individuals) used in these studies. Future experiments within the $C$. breweri - hawkmoth system should address the behavioral function of floral scent and the connection between foraging experiences, associative learning, receptor endowment and olfactory physiology (e.g. Vet et al., 1990; Gerber et al., 1996).

\section{Acknowledgements}

This research was funded by a Sigma Xi Grant-in-Aid of Research and by the Theodore Roosevelt Fund of the American Museum of Natural History. We thank R. Flath for his chemical expertise and for some of the stimulant compounds used in this study. RAR thanks C. and P. Adams, B. Bowman and A. and P. Howard for their kind hospitality during this study, and C. Conlan, S. Miller, K. Osborne and J. Tuttle for generously sharing their knowledge of Sphinx biology.

\section{References}

Baker, H., 1961. The adaptation of flowering plants to nocturnal and crepuscular pollinators. Quarterly Review of Biology 36: 64-73.

Bartholomew, B. \& T. Casey, 1978. Oxygen consumption of moths during rest, pre-flight warm-up, and flight in relation to body 
size and wing morphology. Journal of Experimental Biology 76: 11-25.

Beker, R., A. Dafni, D. Eisikowitch \& U. Ravid, 1989. Volatiles of two chemotypes of Majorana syriaca L. (Labiatae) as olfactory cues for the honeybee. Oecologia 79: 446-451.

Brantjes, N. B. M., 1973. Sphingophilous flowers, function of their scent. In: N. B. M. Brantjes (ed), Pollination and Dispersal. Dept. Botany, Nijmegen, pp. 27-46.

Brantjes, N. B. M., 1978. Sensory responses to flowers in night flying moths. In: A. J. Richards (ed.), The Pollination of Flowers by Insects. Academic Press, London, pp. 13-19.

Chase, V. \& P. Raven, 1975. Evolutionary and ecological relationships between Aquilegia formosa and A. pubescens (Ranunculaceae), two perennial plants. Evolution 29: 474-486.

Dickens, J. C., J. Smith \& D. Light, 1993. Green leaf volatiles enhance sex attractant pheromone of the tobacco budworm, Heliothis virescens (Lep.: Noctuidae). Chemoecology 4: 175177.

Dobson, H., 1994. Floral volatiles in insect biology. In: E. Bernays (ed.), Insect-Plant Interactions, Vol. V. CRC Press, Boca Raton, FL, pp. 47-81.

Dudareva, N., L. Cseke, V. Blanc \& E. Pichersky, 1996. Evolution of floral scent in Clarkia: novel patterns of S-linalool synthase gene expression in the C. breweri flower. The Plant Cell 8: 1137-1148.

Faegri, K. \& L. van der Pijl, 1979. The Principles of Pollination Ecology. Third ed. Pergamon Press, Oxford.

Flath, R., D. Light, E. Jang, T. Mon \& J. John, 1990. Headspace examination of volatile emissions from ripening papaya (Carica papaya L., Solo Variety). Journal of Agricultural and Food Chemistry 38: 1060-1063.

Fleming, R., 1970. Food plants of some adult sphinx moths (Lepidoptera: Sphingidae). The Michigan Entomologist 3: 17-23.

Fröhlich, O., C. Duque \& P. Schreier, 1989. Volatile constituents of Curuba (Passiflora mollissima) fruit. Journal of Agricultural and Food Chemistry 37: 421-425.

Gabel, B, D. Thiery, V. Suchy, F. Marion-Poll, P. Hradsky \& P. Farkas, 1992. Floral volatiles of Tanacetum vulgare attractive to Lobesia botrana females. Journal of Chemical Ecology 18: 693-700.

Gerber, B., N. Beberzahn, F. Hellstern, J. Klein, O. Kowalsky, D. Würstemberg \& R. Menzel, 1996. Honey bees transfer olfactory memories established during flower visits to a proboscis extension paradigm in the laboratory. Animal Behavior 52: 1079-1085.

Grant, V., 1952. Isolation and hybridization between Aquilegia formosa and A. pubescens. Aliso 2: 341-360.

Grant, V., 1983. The systematic and geographical distribution of hawkmoth flowers in the temperate North American flora. Botanical Gazette 144: 439-449.

Gregory, D., 1963. Hawkmoth pollination in the genus Oenothera I. Aliso 5: 357-384.

Gregory, D., 1964. Hawkmoth pollination in the genus Oenothera II. Aliso 5: 385-419.

Haber, W. \& G. Frankie, 1989. A tropical hawkmoth community: Costa Rican dry forest Sphingidae. Biotropica 21: 155-172.

Heath, J. \& P. Adams, 1965. Temperature regulation in the sphinx moth during flight. Nature 208: 309-310.

Heinrich, B., 1971. Temperature regulation of the sphinx moth, Manduca sexta I. Flight energetics and body temperature during free and tethered flight. Journal of Experimental Biology 54: $141-152$.

Hodges, R., 1971. The Moths of North America, vol. 1: Sphingidae. E. W. Classey, Ltd. England.
Hodges, S., 1995. The influence of nectar production on hawkmoth behavior, self pollination and seed production in Mirabilis multiflora (Nyctaginaceae). American Journal of Botany 82: 197-204.

Kaiser, R., 1991. Trapping, investigation and reconstruction of floral scents. In: P. Müller \& D. Lamparsky (eds), 'Perfume: Art, Science and Technology'. Elsevier Appl. Sci., Inc., New York, pp. 213-248.

Kaiser, R., 1993. The Scents of Orchids. Elsevier, Editiones Roche, Basel.

Kislev, M., Z. Kraviz \& J. Lorch, 1972. A study of hawkmoth pollination by a palynological analysis of the proboscis. Israel Journal of Botany 21: 57-75.

Knoll, F., 1925. Lichtsinn und Blutenbesuch des Falters von Deilephila livornica. Journal of Comparative Physiology 2: 329-378.

Knudsen, J. \& L. Tollsten, 1993. Trends in floral scent chemistry in pollination syndromes: floral scent composition in mothpollinated taxa. Botanical Journal of the Linnean Society 113: 263-284.

Knudsen, J. \& L. Tollsten, 1995. Floral scent in bat pollinated plants: a case of convergent evolution? Botanical Journal of the Linnean Society 118: 45-57.

Kugler, H., 1971. Zur bestaubung grossblumiger Datura-Arten. Flora 160: 511-517.

Light, D., R. Flath, R. Buttery, F. Zalom, R. Rice, J. Dickens \& E. Jang, 1993. Host-plant green-leaf volatiles synergize the synthetic sex pheromones of the corn earworm and codling moth (Lepidoptera). Chemoecology 4: 145-152.

Light, D., E. Jang \& J. Dickens, 1988. Electroantennogram responses of the Mediterranean fruit fly, Ceratitis capitata, to the volatile constituents of nectarines. Entomologia Experimentalis et Applicata 63: 13-26.

MacSwain, J., P. Raven \& R. Thorp, 1973. Comparative behavior of bees and Onagraceae IV: Clarkia bees of the western United States. University of California Publications in Entomology 70: $1-80$.

McGrath, M. \& C. Karahadian. 1994. Evaluation of physical, chemical and sensory properties of Pawpaw fruit (Asimina triloba) as indicators of ripeness. Journal of Agricultural and Food Chemistry $42:$ 968-974.

Miller, R., 1978. The pollination ecology of Aquilegia elegantula and $A$. caerulea (Ranunculaceae) in Colorado. American Journal of Botany 65: 406-414.

Nilsson, L. A., 1983. Processes of isolation and introgressive interplay between Platanthera bifolia (L.) Rich. and P. chlorantha (Custer) Reichb. (Orchidaceae). Botanical Journal of the Linnaean Society 87: 325-350.

Nilsson, L. A., L. Jonsson, L. Rason \& E. Randrianjohany, 1985. Monophily and pollination mechanisms in Angraecum arachnites Schltr. (Orchidaceae) in a guild of long-tongued hawkmoths (Sphingidae) in Madagascar. Biological Journal of the Linnean Society 26: 1-19.

Pichersky, E., R. Raguso, E. Lewinsohn \& R. Croteau, 1994. Floral scent production inClarkia (Onagraceae) I. Localization and developmental modulation of monoterpene emission and linalool synthase activity. Plant Physiology 106: 1533-1540.

Raguso, R., 1995. Mechanisms of floral scent production and hawkmoth pollination in Clarkia breweri (Onagraceae). PhD dissertation, Univ. of Michigan, $356 \mathrm{pp}$.

Raguso, R. \& E. Pichersky, 1995. Floral volatiles from Clarkia breweri and C. concinna (Onagraceae): recent evolution of floral scent and moth pollination. Plant Systematics \& Evolution 194: 55-67.

Raguso, R., D. Light \& E. Pichersky, 1996. Electroantennogram responses of Hyles lineata (Sphingidae: Lepidoptera) to volatile 
compounds from Clarkia breweri (Onagraceae) and other mothpollinated flowers. Journal of Chemical Ecology 22: 1735-1766.

Reed, D., E. Underhill \& E. Giblin, 1987. Attraction of sphingid moths (Lepidoptera: Sphingidae) to 10,12-hexadecadienyl aldehydes and acetates: evidence of pheromone components. Journal of Chemical Ecology 13: 931-942.

Silberbauer-Gottsberger, I. \& G. Gottsberger, 1975. Uber sphingophile Angiospermen Brasiliens. Plant Systematics and Evolution 123: $157-184$.

Sokal, R. \& F. Rohlf, 1981. Biometry. Second Edition. W. H. Freeman \& Co., San Fancisco, CA.

Tinbergen, N., 1958. Curious Naturalists. Basic Books, Inc., New York, NY.

Tollsten, L., 1993. Fragrance chemotypes of Platanthera (Orchidaceae) - the result of adaptation to pollinating moths? Nordic Journal of Botany 13: 607-613.
Vet, L. E. M., R. deJong, W. van Giessen \& J. Visser, 1990. A learning-related variation in electroantennogram responses of a parasitic wasp. Physiological Entomology 15: 243-247.

Visser, J. \& D. Avé, 1978. General green leaf volatiles in the olfactory orientation of the Colorado beetle, Leptinotarsa decemlineata. Entomologia Experimentalis et Applicata 24: 538-549.

Visser, J., S. van Straten \& H. Maarse, 1979. Isolation and identification of volatiles in the foliage of potato, Solanum tuberosum, a host plant of the Colorado beetle, Leptinotarsa decemlineata. Journal of Chemical Ecology 5: 13-25.

White, R., R. Stevenson, R. Bennett, D. Cutler \& W. Haber, 1994. Wavelength discrimination and the role of ultraviolet vision in the feeding behavior of hawkmoths. Biotropica 26: 427-435. 